\title{
The emotional bank account, the consultation, and the credit crunch
}

One of the first patients I remember helping as a GP trainee (as we were called in those days) was a man in his 40 s with a non-specific abdominal pain, who had been coming for 2 years to see different doctors. As he had health insurance an endoscopy was swiftly arranged which showed duodenitis and Helicobacter pylori. He at last felt well and his life was transformed. From then on he would only come to see me, even though I was the trainee. He told me how he was doing more exercise and getting his life in order. At that point I moved on since we did 3 months in general practice at the beginning and 9 months at the end of our VTS.

A few years later I went to a seminar on leadership and the speaker was discussing how we build up a trust account with those we deal with. Every time we do something good we make a deposit into their trust account. As I have reflected on this I realise that it is also true in our dealings with patients. The appropriate diagnosis, the kind word, the effective treatment, the concern for the person and their family, are all ways of making deposits into their trust accounts. Another term for the trust account is the 'emotional bank account', a term used by Covey. ${ }^{1}$

Of course it is also possible to make withdrawals from the emotional bank account/trust account. In our teams every mistake or criticism of a person leads to a withdrawal. Similarly the missed diagnoses, the lack of empathy or concern, the hurried consultation, also make withdrawals. However, if we are in credit in our trust accounts we can also make withdrawals deliberately.

The gentleman I wrote about earlier came back to see me in my final 9 months as a trainee. He had put on weight, he was not exercising, and he was depressed. When I saw him I pointed out that he had really let his body go to seed and asked him what had happened and what he was going to do about it. $\mathrm{He}$ told me the story (since I was in credit in his trust account), that he had felt so well that he started an affair with his secretary, and his wife on discovering it had thrown him out of the home. Then his affair had ended too. The challenge to him was a withdrawal from his trust account, but because I was in credit I could get away with it, and even suggest aiming for a reconciliation. I have challenged people I have met for the first time and things have not gone so well, on reflection because there is no credit in my account and it has sent me into deficit.

The emotional bank account applies to two other areas of our work: one is with our staff and colleagues - do we work to make deposits into their trust accounts? If so, the withdrawals we make - asking for a favour, swapping duties, asking the receptionists to work extended hours, for instance, will be easier. Secondly, it applies to our relationships with the general public. Are we in credit or deficit? Despite the negative spin in the media against GPs as being the fat cats of medicine and resistant to change, are we still trusted? And what are we doing to make deposits into the trust accounts of government, SHAs, PCTs, and the public?

How does this apply to the consultation? I for one certainly have got confused by the plethora of consultation models each with another stage. There are many models, most of which show the need to build up trust by establishing rapport and connecting and communicating in a patient-centred way. However, trust can also be built by medical competence and skills, which is absent from some of the models, except in terms of safety netting, for instance. ${ }^{2}$ If we have built up trust/connected/established rapport, then we can also challenge unhealthy behaviour from a position of strength.

Therefore, given the current economic climate, the key message to medical students and trainees is perhaps the same that one would give to investment bankers - don't make account withdrawals before you have some credit, because overdrafts in health care come with very heavy penalties. You may never be able to pay back the interest!

\section{Nick Wooding}

\section{REFERENCES}

1. Covey S. The seven habits of highly effective people. Cambridge: Simon \& Schuster, 1989.

2. Neighbour R. The inner consultation - how to develop an effective and intuitive consulting style (2nd edn). Oxford: Radcliffe Publishing, 2005.

DOI: 10.3399/bjgp09X407027 